NUKHBATUL 'ULUM : Jurnal Bidang Kajian Islam

Vol. 5, No. 1 (2019) : Hal. 15-25

Website: https://journal.stiba.ac.id

ISSN : 2685-7537 (online) 2338-5251 (Printed)

\title{
TINJAUAN AKIDAH ISLAM TERHADAP ADAT MAPPALILI DI BALLA LOMPOA KELURAHAN BAJU BODOA KECAMATAN MAROS BARU KABUPATEN MAROS SULAWESI SELATAN
}

\section{Islamic Faith Viewpoint on the Tradition of Mappalili in Balla Lompoa, Baju Bodoa, Maros Baru District, Maros Regency}

\author{
Nuraeni Novira \\ Sekolah Tinggi Ilmu Islam dan Bahasa Arab (STIBA) Makassar \\ Email : nuraeninovira@gmail.com@gmail.com \\ Auliani Ahmad \\ Sekolah Tinggi Ilmu Islam dan Bahasa Arab (STIBA) Makassar \\ Email : nuraeninovira@gmail.com@gmail.com
}

\begin{tabular}{|c|c|}
\hline Keywords : & $A B S T R A C T$ \\
\hline tradition, mappalili, tauhid, faith & $\begin{array}{l}\text { This study aimed to know: (1) the form of the tradition of Mappalili in Balla Lompoa, Baju } \\
\text { Bodoa, Maros Baru District, Maros Regency; (2) community's response to the tradition of } \\
\text { Mappalili in Balla Lompoa, Baju Bodoa, Maros Baru District, Maros Regency; and (3) } \\
\text { viewpoint of Islamic faith on the tradition of Mappalili in Balla Lompoa, Baju Bodoa, Maros } \\
\text { Baru District, Maros Regency. The type of research was descriptive-qualitative, that was to } \\
\text { understand the phenomena or occurrences regarding the tradition performed by research subjects } \\
\text { that resulted descriptive data in the form of oral information from some people who were } \\
\text { considered to know better, and behaviors and observed objects. The result of the study shows } \\
\text { that: (1) the tradition of Mappalili is a series of unique traditional ceremonies of Karaeng } \\
\text { Marusu which essentially implies the make-use of royal tools in the royal rice field which was } \\
\text { named Turannu to plow the rice field area using the relic of Pajekeona Karaenga ri Marusu } \\
\text { which is conducted traditionally; (2) good responses of community to the traditional ritual of } \\
\text { Mappalili is excessive, they still orient themselves, and the people who work on the rice fields } \\
\text { and farmer groups make agreement with the rice field owners on that they are not to start the } \\
\text { activities of working on their fields before the traditional ritual of Mappalili is held; (3) } \\
\text { Traditional ritual of Mappalili and all of its series of events, including pa'jeko, beating drums } \\
\text { with its accompaniment, prayers, and wishes of this party are against the monotheism in terms } \\
\text { of Rububiyab and Ulubiyah. }\end{array}$ \\
\hline Kata kunci : & ABSTRAK \\
\hline adat, mappalili, tauhid, akidab & $\begin{array}{l}\text { Penelitian ini bertujuan untuk mengetahui : (1) bentuk adat Mappalili di Balla } \\
\text { Lompoa Kelurahan Baju Bodoa Kecamatan Maros Baru Kabupaten Maros; (2) } \\
\text { respons masyarakat terhadap adat Mappalili di Balla Lompoa Kelurahan Baju } \\
\text { Bodoa Kecamatan Maros Baru Kabupaten Maros; dan (3) pandangan akidah } \\
\text { Islam terhadap adat Mappalili di Balla Lompoa Kelurahan Baju Bodoa } \\
\text { Kecamatan Maros Baru Kabupaten Maros. Jenis penelitian ini adalah deskriptif- } \\
\text { kualitatif, yaitu memahami fenomena atau peristiwa mengenai tradisi yang } \\
\text { dilakukan oleh subjek penelitian yang menghasilkan data deskripsi berupa } \\
\text { informasi lisan dari beberapa orang yang dianggap lebih tahu, dan perilaku serta } \\
\text { objek yang diamati. Hasil penelitian menemukan bahwa : (1) adat Mappalili } \\
\text { merupakan serangkaian upacara adat khas Karaeng Marusu yang pada intinya } \\
\text { adalah turunnya alat-alat kerajaan menuju sawah kerajaan yang bergelar Turannu } \\
\text { untuk meluku (membajak) area persawahan dengan memakai benda pusaka } \\
\text { Pajekkona Karaenga ri Marusu yang dilaksanakan secara adat; (2) respon baik dari } \\
\text { masyarakat terhadap ritual adat Mappalili sangatlah besar, mereka masih } \\
\text { mempedomani dan masyarakat yang menggarap sawah dan kelompok tani } \\
\text { sepakat dengan pemilik sawah untuk tidak memulai kegiatan menggarap sawah- } \\
\text { sawah mereka sebelum acara ritual adat Mappalili di selenggarakan; (3) ritual } \\
\text { Adat Mappalili dan segala rangkaian acaranya, di antaranya pajeko, memukul } \\
\text { gendang dengan iringannya, doa dan pengharapan terhadap pesta ini adalah } \\
\text { bertentangan dengan tauhid Rububiyah dan Ulubiyah. }\end{array}$ \\
\hline
\end{tabular}




\section{PENDAHULUAN}

Indonesia memiliki corak budaya sendiri yang berbeda dengan negaranegara lain. Adat dan tradisi yang diwariskan secara turun-temurun dari nenek moyang bangsa Indonesia, masih ada yang memelihara kelestarian dan mempertahankannya. Di antara adat yang masih dipertahankan hingga saat ini adalah adat Mappalili, khususnya di daerah Maros, Sulawesi Selatan.

Pelaksanaan upacara adat Mappalili merupakan serangkaian upacara adat khas Karaeng Marusu yang pada intinya adalah turunnya alat-alat kerajaan menuju sawah kerajaan yang bergelar turannu untuk menggarap area persawahan dengan memakai benda pusaka Pa'jekona Karaenga ri Marusu' yang dilaksanakan secara adat, hal ini dilaksanakan setiap tahun sejak dahulu kala oleh para leluhur mereka sebagai bentuk budaya, meskipun ada beberapa proses ritual adat Mappalili yang tidak sesuai dengan nilai ajaran Islam. Tradisi Adat Mappalili tidak hanya ada di Maros, tetapi juga dilaksanakan di tempat lain seperti di Kabupaten Pangkep. Faktor yang menjadikan adat Mappalili tetap dilestarikan adalah karena merupakan salah satu bentuk syukur masyarakat dan salah satu cara mereka untuk menjaga tanaman padi dari sesuatu yang akan mengganggu atau menghancurkannya.

Berdasarkan pendahuluan di atas, penulis tertarik untuk meneliti lebih dalam lagi tentang adat Mappalili tersebut, khusunya dalam kaitannya dengan akidah Islam. Permasalahan penelitian yang mengemuka untuk dijawab adalah :

1. Bagaimana bentuk Adat Mappalili di Balla Lompoa Kelurahan Baju
Bodoa Kecamatan Maros Baru Kabupaten Maros?

2. Bagaimana respons masyarakat terhadap Adat Mappalili di Balla Lompoa Kelurahan Baju Bodoa Kecamatan Maros Baru Kabupaten Maros?

3. Bagaimana pandangan akidah Islam terhadap Adat Mappalili di Balla Lompoa Kelurahan Baju Bodoa Kecamatan Maros Baru Kabupaten Maros?

Untuk menjawab permasalahan tersebut di atas, penelitian ini dilakukan dengan tujuan untuk mengetahui : (1) bentuk adat Mappalili di Balla Lompoa Kelurahan Baju Bodoa Kecamatan Maros Baru Kabupaten Maros; (2) respons masyarakat terhadap adat Mappalili di Balla Lompoa Kelurahan Baju Bodoa Kecamatan Maros Baru Kabupaten Maros; dan (3) pandangan akidah Islam terhadap adat Mappalili di Balla Lompoa Kelurahan Baju Bodoa Kecamatan Maros Baru Kabupaten Maros.

Penelitian ini adalah peneltian deskriptif-kualitatif, yaitu penelitian yang dilakukan untuk memahami fenomena atau peristiwa mengenai tradisi yang dilakukan oleh subjek penelitian menghasilkan data deskripsi berupa informasi lisan dari beberapa orang yang dianggap lebih tahu, dan perilaku serta objek yang diamati. Lokasi penelitian adat Mappalili dilaksanakan di Kompleks Balla Lompoa, Jalan Balla Lompoa No. 1 Kassikebo Maros, Kelurahan Baju Bodoa, Kecamatan Maros Baru, Kabupaten Maros. Yang mana wilayah Kabupaten Maros adalah suatu wilayah kerajaan yang dikenal sebagai Kerajaan Marusu' yang kemudian bernama Kabupaten Maros. Wilayah kompleks 
NUKHBATUL 'ULUM : Jurnal Bidang Kajian Islam

Vol. 5, No. 1 (2019) : Hal. 15-25

Website: https://journal.stiba.ac.id

ISSN : 2685-7537 (online) 2338-5251 (Printed)

Balla Lompoa mencakup 17 Kepala Keluarga (KK) dan bersuku Bugis Makassar.

\section{PEMBAHASAN}

\section{A. Adat Mappalili}

Menurut bahasa, Mappalili berasal dari kata Palili yang memiliki makna untuk menjaga tanaman padi dari sesuatu yang akan mengganggu atau menghancurkannya. Dan Mappalili adalah ritual turun-temurun yang dipegang oleh masyarakat wilayah Sulawesi Selatan. ${ }^{1}$

Tidak diketahui secara pasti sejak tahun berapa awal terbentuknya adat Mappalili, adapun pelaksanaan adat Mappalili ini sejak kemunculannya benda pusaka yang disebut Pajjeko.

Pajeko termasuk salah satu benda pusaka yang sangat unik. Kemunculan benda pusaka yang disebut Pa'jeko sejak mairatnya Raja Marusu' ke enam, raja yang bergelar Karaeng Angsakayya ri Marusu'. Bahkan ada julukan lain darinya yaitu $\mathrm{Ri}$ Maru' Karaeng Angsakayya Binangayya.

Adat Mappalili hanya dilaksanakan sekali dalam setahun, sementara musim panen minimal dua kali hingga tiga kali, sedangkan zaman dahulu hanya sekali, yaitu saat musim hujan saja berhubung belum adanya sistem pengairan, jadi tidak memungkinkan sawah diolah lebih dari satu kali karena hanya peruntukannya tadah hujan, dan awal permulaan musim hujan yaitu pada

${ }^{1}$ http://youchenkymayeli.blogspot.com./2012 /10/upacara-mappalili-turun-sawah-di.html, (diakses pada tanggal 31 maret 2018). bulan November, di situlah dimulai upacara adat Mappalili diselenggarakan.

Petani memulai musim tanam seharusnya saat musim penghujan, yakni sekitar bulan November, namun kemarau panjang yang melanda Maros dan beberapa Kabupaten lainnya di Sulawesi Selatan, diprediksi akan membuat musim tanam tersebut mundur dari jadwal biasanya.

Meskipun demikian, upacara adat untuk memulai musim tanam di Maros atau biasa disebut Upacara Mappalili tetap akan dilaksanakan tanggal 16-17 November mendatang di Istana Balla Lompoa Marusu, Lingkungan Kassikebo, jalan Taqwa No.9 Kelurahan Baju Bodoa Kecamatan Maros Baru Kabupaten Maros. Hal itu disampaikan oleh salah seorang tokoh dari Lembaga Adat Karaeng Marusu, A. Abdul Hafid Tajuddin Karaeng $\mathrm{Opa}^{2}$

Abdul Hafid mengatakan, jadwal tersebut sudah menjadi jadwal tahunan yang sudah ditetapkan kecuali bertepatan dengan bulan Ramadhan atau Hari besar Islam lainya, maka jadwal akan disesuaikan.

Abdul Hafid menjelaskan, upacara ini merupakan simbol dimulainya musim tanam, tetapi jika musim tanam belum bisa dilakukan akibat kemarau, maka petani tentu saja akan menyesuaikan. Tetapi upacara adat ini tetap dilaksanakan sesuai yang dijadwalkan.

Rangkaian upacara adat Mappalili dimulai turunya alat-alat kerajaan yang

${ }^{2}$ http://www.marosfm.com/2015/11/kendati -elnino-upacara-adat-mappalili-di-maros-tetapdilaksanakan-sesuai-jadwal-tahunan, (diakses pada tanggal 14 Mei 2018). 
saat ini tersimpan di Balla Lompoa, Kassikebo Maros, pada sore hari, tanggal 16 November, kemudian dilanjutkan dengan penerimaan tamu biasanya dari lingkup pejabat dan tokoh masyarakat dilaksanakan sekitar pukul 19.00 sampai pukul 24.00 .

Kemudian, pada subuh hari tanggal 17 November, usai sholat subuh, benda pusaka "Pajjekona Karaenga ri Marusu" menuju sawah kerajaan yang disebut "Torannu" yang menyimbolkan dimulainya musim tanam bagi petani. ${ }^{3}$

Adat Mappalili merupakan serangkaian upacara adat khas Karaeng Marusu yang pada intinya adalah turunnya alat-alat kerajaan menuju sawah kerajaan yang bergelar Turannu untuk meluku (membajak) area persawahan dengan memakai benda pusaka Pajekkona Karaenga ri Marusu yang dilaksanakan secara adat, hal ini dilaksanakan setiap tahun sejak dahulu kala oleh para leluhur mereka sebagai bentuk budaya.Yang dilaksanakan setiap tahunnya yaitu pada bulan November.

Ada beberapa jenis adat istiadat yang telah lama ditekuni oleh masyarakat yang dapat dikatakan tidak sesuai dengan ajaran Islam, disebabkan karena adanya unsur yang bisa menjerumuskan kedalam kemusyirikan, seperti halnya dalam pelaksanaan ritual adat Mappalili ini yang dirangkaikan dengan gendang kebesaran kerajaan, dan masyarakat tidak akan memulai pekerjaan sawah sebelum ritual adat Mappalili diselenggarakan, yang dimana masyarakat sudah menjadikan adatistiadat ini menjadi suatu hal yang wajib bagi mereka.

3 http://www.marosfm.com/2015/11/kendati -elnito-upacara-adat-mappalili-di-maros-tetap-

\section{B. Prosesi Ritual Adat Mappalili di Maros.}

Prosesi ritual ini diselenggarakan pada setiap bulan November, yang mana setiap yang turun berpartisipasi wajib melaksanakan beberapa hal, diantaranya seperti :

1. Sarapan dengan memakan Songkolo', Cangkuli', dan Palopo'.

2. Pakaian yang dikenakan bagi keluarga pemangku adat adalah pakaian adat Bugis-Makassar (minimal memakai Kopiah).

3. Undangan menyesuaikan.

Adapun prosesi yang akan berlangsung diantaranya:

1. Kamis, 16 November:

a. Jam 07.00 Wita: Para pegawai kerajaan berkumpul di Balla lompoa untuk menurungkan dan mempersiapkan alat dan benda pusaka kerajaan yang ada hubungannya dengan upacara adat Mappalili;

b. Jam 09.00 Wita: Para pegawai kerajaan menyiapkan dan merawat alat dan benda pusaka kerajaan sesuai dengan tugas masing-masing kemudian menempatkan dan menatanya diruangan tertentu yang disebut ruangan Salewanganna Balla Lompoa;

c. Jam 11.00 Wita: Gedung kebesaran kerajaan beserta iringannya mulai dimainkan pertanda acara pesta budaya adat tahunan Mappalili sudah dimulai;

d. Jam 14.00 Wita: Kegiatan pemeliharaan (perawatan,

dilaksanakan-sesuai-jadwal-tahunan, (diakses pada tanggal 8 Mei 2018). 
penggantian, pembersihan, Tompang dan pencucian alat dan benda pusaka kerajaan dilakukan oleh masing-masing pegawai kerajaan sesuai tugas masingmasing;

e. Jam 20.00 Wita: Acara silaturahmi bersama para Dewan Adat, Pemangku Adat, Petinggi Adat, Pemuka Adat, Rumpung keluarga besar lainnya, para petani, buru tani, dan undangan lainnya. Pada kempatan ini selain tema khusus seperti biasanya untuk pokok acara adalah Singkronisasi jadwal tanam para petani dan pengembangan kegiatan upacara budaya adat khas Karaeng Marusu;

f. Jam 22.00 Wita: Acara dzikir, do'a dan pembuatan kapur sirih atau Bungasa Panggajai serta siarah pada Riolo Kalabbiranna Kalampoanga ri Marusu, sebagai tanda mohon restu serta wujud syukur kehadirat Allah swt bahwa musim tanam akan segera dimulai.

2. Jum'at, 17 November:

a. Jam 04.45 Wita: Persiapan arakarakan menuju kesawah kerajaan yang bergelar Turannu;

b. Jam 05.15 Wita: Pelaksanaan meluku (membaja) sawah dengan memakai benda pusaka Pajjeko Kalampoanna Karaenga ri Marusu secara adat sebagai kegiatan inti dalam pelaksanaan upacara adat Mappalili;

c. Jam 07.00 Wita: Kegiatan pembenahan atau penyimpanan, semua benda dan alat kerajaaan

${ }^{4}$ Hasil Wawancara dengan Abdul Waris Tadjuddin (Karaeng Sioja), Pemangku Adat Karaeng Marusu, pada tanggal 02 Juni 2018. yang telah dipakai pada upacara ini untuk dikembalikan pada tempatnya masing-masing oleh para pinati dan pegawai

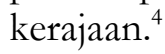

\section{Respon Masyarakat Terhadap Adat Mappalili}

Respon baik dari masyarakat terhadap ritual adat Mappalili sangatlah besar, mereka masih mempedomani sehingga masyarakat yang menggarap sawah serta sekelompok tani sepakat dengan pemilik sawah untuk tidak memulai kegiatan menggarap sawah-sawah mereka sebelum acara ritual adat Mappalili di selenggarakan. Masyarakat pun sangat bersinergi untuk memajukan adat istiadat yang diadakan di Balla Lompoa yang di mana pemerintahan terdahulu berada dalam naungan Balla Lompoa. ${ }^{5}$

Dilihat dari segi tata aturannya, ada tujuh tata aturan yang berlaku di daerah-daerah Gallaranna yang dipedomani oleh masyarakat di wilayah Kecamatan Maros Baru, Kabupaten Maros, diantaranya tata aturan waktu, tata aturan hukum, tata aturan kesepakatan sosial dan lain sebagainya.

Adapun yang dipedomani masyarakat Kecamatan Maros Baru Kabupaten Maros yaitu tidak adanya waktu yang direncanakan ataupun yang ditetapkan untuk memulai menggarap sawah sebelum acara ritual adat Mappalili berlangsung. Karena tradisi ini sudah menjadi salah satu kewajiban yang harus dilaksanakan setiap tahunnya di tengah-tengah masyarakat Kelurahan

${ }^{5}$ Hasil Wawancara dengan Maulida (Masyarakat), pada tanggal 06 Juni 2018. 
NUKHBATUL 'ULUM : Jurnal Bidang Kajian Islam

Vol. 5, No. 1 (2019) : Hal. 15-25

Website: https://journal.stiba.ac.id

ISSN : 2685-7537 (online) 2338-5251 (Printed)

Baju Bodoa Kecamatan Maros Baru Kabupaten Maros.

Ritual adat Mappalili di Maros adalah sebuah tradisi yang sudah menjadi suatu hal kewajiban di tengah-tengah masyarakat Kecamatan Maros Baru. Masyarakat Kecamatan Maros Barulah yang sangat berantusias selalu menunggu kehadiran pelaksanaan adat Mappalili.

Berhubungan dengan antusiasnya masyarakat di wilayah Kecamatan Maros Baru terhadap ritual adat Mappalili sehingga semua masyarakat sangat ingin terlibat dalam pelaksanaan ritual adat Mappalili tersebut. Masyarakat selalu menanti proses inti dari ritual adat Mappalili ini. Sangat terlihat dengan jelas saat masuknya waktu proses adat Mappalili sudah akan dimulai maka setelah selesainya sholat subuh maka masyarakat langsung membawa masing-masing simbol alatalat mereka seperti cangkul. Dan setelah prosesi ritual adat Mappalili itu berlangsung, maka masyarakat berlomba-lomba untuk memulai mencangkul sawahnya masing-masing pertanda mulainya pekerjaan sawah (siapnya diolah sawah tersebut).

Adat Mappalili juga termasuk tata aturan hukum gadai-menggadai, jualmenjual yang dipedomani namun hal ini tidak tertulis, karena dahulu kala yang sangat diperhatikan masyarakat adalah suatu hal yang bersifat lisan dari pada yang bersifat tulisan.

Adapun sawah yang digunakan dalam prosesi ritual adat Mappalili adalah sawah tertentu, yaitu sawah kerajaan

${ }^{6}$ Hasil Wawancara dengan Abdul Waris Tadjuddin (Karaeng Sioja), Pemangku Adat Karaeng Marusu, pada tanggal 02 Juni 2018. 
Islam sebagai agama yang syariatnya telah sempurna berfungsi untuk mengatur segenap makhluk hidup yang ada dibumi. Setiap aturan-aturan, anjuran, perintah tentu saja akan memberi dampak positif dan setiap larangan yang diindahkan membawa keberuntungan bagi hidup manusia. Salah satu larangan yang akan membawa maslahat bagi manusia adalah menjauhkan diri dari kebiasaankebiasaan nenek moyang terdahulu yang bertentangan dengan ajaran Islam. Hal tersebut sebagaimana yang Allah swt firmankan dalam al-Qur'an.

Dalil dari al-Qur'an yaitu Q.S. alBaqarah/2:170 :

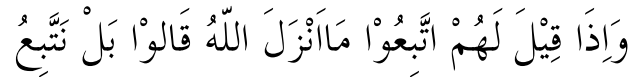

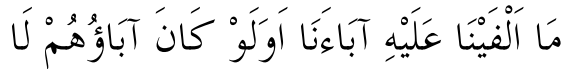

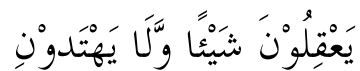

Terjemahnya:

Dan apabila dikatakan kepada mereka, "Ikutilah apa yang telah di turunkan Allah ," mereka menjawab, “(Tidak!) Kami mengikuti pada nenek moyang kami (melakukannya)". Padahal nenek moyang mereka itu tidak mengetahui apa pun, dan tidak mendapat petunjuk. ${ }^{7}$

Dalil dari al-Qur'an yaitu Q.S. alMaidah/5:104 :

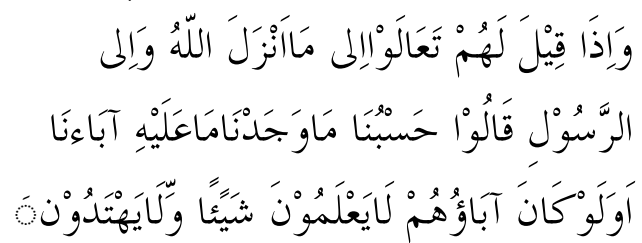

Terjemahnya:

7Departemen Agama RI, al-Qur'an dan Terjemahannya, (t.Cet;Bandung: PT Sygma Examedia Arkanleem), h. 26.
Dan apabila dikatakan kepada mereka, "Marilah (mengikuti) apa yang diturunkan Allah dan (mengikuti) Rasul". Mereka menjawab, "Cukuplah bagi kami apa yang kami dapati nenek moyang kami (mengerjakannya)". Apakah (mereka akan mengikuti) juga nenek moyang mereka walaupun nenek moyang mereka itu tidak mengetahui apa-apa dan tidak (pula) mendapat petunjuk?.

Kedua ayat tersebut menjelaskan kepada kita tentang orang-orang yang lebih patuh pada ajaran dan perintah nenek moyangnya dari pada syari'at yang diwahyukan oleh Allah swt didalam al-Qur'an. Seperti adanya kepercayaan-kepercayaan tertentu pada ritual-ritual yang menjanjikan keselamatan, ketenangan hidup, penolak bala yang menjadi salah satu tradisi masyarakat Indonesia di berbagai daerah.

Adanya syariat tidak berupaya menghapuskan tradisi atau adatistiadat, Islam menyaringi tradisi tersebut agar setiap nilai-nilai yang dianut dan diaktualisasikan oleh masyarakat setempat tidak bertolak belakang dengan Syariat. Sebab tradisi yang dilakukan oleh setiap suku bangsa yang nota bene beragama Islam tidak boleh menyelisihi syariat. Karena kedudukan akal tidak akan pernah lebih utama dibandingkan wahyu Allah swt. Inilah pemahaman yang esensi lagi krusial yang harus dimiliki oleh setiap Muslim.

8Departemen Agama RI, al-Qur'an dan Terjemahannya, (t.Cet;Bandung: PT Sygma Examedia Arkanleem), h. 125. 
Keyakinan Islam sebagai agama universal dan mengatur segala sendisendi kehidupan bukan hanya pada hubungan transendental antara hamba dan pencita tetapi juga aspek hidup lainnya seperti ekonomi, sosial, budaya, politik dan lain sebagainya. Kadangkala pemahaman parsial inilah yang masih diyakini oleh ummat Islam. Oleh karena itu, sikap syariat Islam terhadap adat-istiadat senantiasa mendahulukan dalil-dalil dalam al-Qur'an dan hadis dibanding adat atau tradisi.

Dalil dari al-Qur'an yaitu Q.S. alAhzab/33:36:

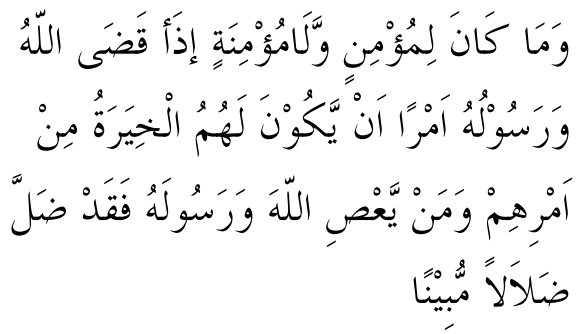

Terjemahnya:

Dan tidaklah pantas bagi laki-laki yang mukmin dan perempuan yang mukmin, apabila Allah dan Rasul-Nya telah menetapkan suatu ketetapan, akan ada pilihan (yang lain) bagi mereka tentang urusan mereka. Dan barang siapa mendurhakai Allah dan Rasul-Nya, maka sungguh, dia telah tersesat, dengan kesesatan yang nyata. ${ }^{9}$

\section{Adat Mappalili Dalam Perspektif Akidah Islam.}

Mappalili adalah menjaga tanaman padi dari sesuatu yang akan merusaknya, dan pa'jeko merupakan salah satu benda

\footnotetext{
${ }^{9}$ Departemen Agama RI, al-Qur'an dan Terjemahannya, (t.Cet;Bandung: PT Sygma Examedia Arkanleem), h. 423.

10 Departemen Agama RI, al-Qur'an dan Terjemahannya, (t.Cet;Bandung: PT Sygma Examedia Arkanleem), h. 157.
}

pusaka yang sangat unik milik Raja Marusu yang diyakini oleh warga Maros dapat mengalirkan air sungai sebagai pengairan sawah. Keduanya sangat bertentangan dengan Rububiyah Allah swt, yakni menciptakan, pengatur segala urusan, menjaga seluruh makhluk dari kerusakan, menurunkan hujan,mengalirkan sungai, member rezeki dari hasil tumbuh-tumbuhan.

Dalil dari al-Qur'an yaitu Q.S. alA'raf/7:54:

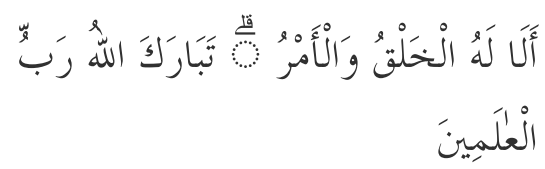

Terjemahnya:

Ingatlah, menciptakan dan memerintah hanyalah hak Allah. Maha Suci Allah, Tuhan semesta alam.10

Dalil dari al-Qur'an yaitu Q.S. Thaha/20:53-54.

Terjemahnya:

Yang telah menjadikan bagimu bumi sebagai hamparan dan Yang telah menjadikan bagimu di bumi itu jalanja]an, dan menurunkan dari langit air hujan. Maka Kami tumbuhkan dengan air hujan itu berjenis-jenis dari tumbuhtumbuhan yang bermacam-macam. Makanlah dan gembalakanlah binatang-binatangmu. ${ }^{11}$

Keesaan Allah swt dalam kekuasaan, pemilikan, dalam hal pemberian rezeki, dan menurunkan hujan serta

11 Departemen Agama RI, al-Qur'an dan Terjemahannya, (t.Cet;Bandung: PT Sygma Examedia Arkanleem), h. 315. 
pengaturanNya terhadap segala sesuatu, adalah bukti atas Rububiyah Allah swt. ${ }^{12}$

Memukul gendang kebesaran kerajaan beserta iringannya yang dimainkan saat acara pesta budaya adat tahunan Mappalili dimulai, yang dimana hal tersebut tidak dibenarkan dalam alQur'an maupun hadis.

Dalil dari al-Qur'an yaitu Q.S. alBaqarah/2:208:

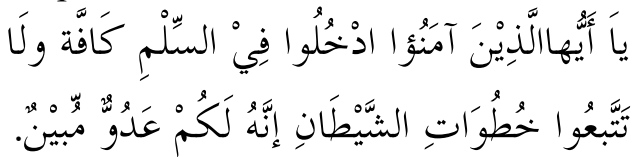

Terjemahnya:

Wahai orang-orang yang beriman! Masuklah ke dalam Islam secara keseluruhan, dan janganlah kamu ikuti langkah-langkah setan. Sungguh, ia musuh yang nyata bagimu. ${ }^{13}$

Dalil tidak diperbolehkannya bermain gendang:

Dari ibnu Abbas ra, Rasul saw bersabda:

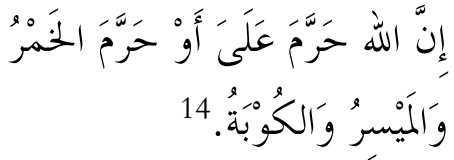

Artinya:

Sesungguhnya Allah telah mengharamkan melalui lidahku, atau mengharamkan khamar (minuman yang memabukkan), maisir (perjudian), dan kubah (gendang).

12 Syaikh Abu Bakar Jabir Al Jazairy, Minhajul Muslim, Terj. Ikhanuddin Abdullah dan Taufik Aulia Rahman, Pedoman Hidup Harian Seorang Muslim (Jakarta: Ummul Qura, 2014), h. 37-39.

${ }^{13}$ Departemen Agama RI, al-Qur'an dan Terjemahannya. (t.Cet;Bandung: PT Sygma Examedia Arkanleem), h. 32.
Lalu Sufyan berkata: maka aku bertanya pada Ali bin Budzaimah salah seorang rawi tentang kubah (gendang), maka beliau berkata: "Thobl (gendang)." (HR.Ahmad 2476), Abu Daud (3696).

Rangkaian acara adat mappalili berupa dzikir, doa, pengharapan dan pembuatan kapur sirih atau bungasa panggajai sebagai tanda rasa syukur kehadirat Allah swt bahwa musim tanam segera dimulai, agar padi yang ditanamnya dapat tumbuh dengan baik agar menghasilkan panen yang melimpah, serta acara torannu yang merupakan symbol dari Makassar yang menjadi pusat perhatian dengan harapan bisa menjadi symbol kebahagiaan dan kesejahteraan bagi masyarakat. Kedua fenomena tersebut di atas sangat bertentangan dengan Ulubiyah Allah swt, karena tidak menggantungkan harapan dan doa sepenuhnya kepada Allah swt. ${ }^{15}$

Dalil dari al-Qur'an yaitu Q.S. alBaqarah/2:163:

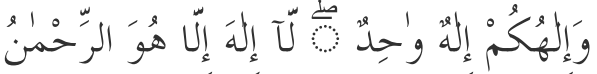

$$
\begin{aligned}
& \text { الرِِّحِمُ }
\end{aligned}
$$

Terjemahnya:

Dan Tuhanmu adalah Tuhan Yang Maha Esa; tidak ada Tuhan melainkan 
Dia Yang Maha Pemurah lagi Maha Penyayang. ${ }^{16}$

Jika setiap makhluk diatur oleh Allah swt, dengan arti bahwa Dialah satusatunya yang menciptakan, memberi rezeki, mengatur segala urusan, dan mengambil tindakan terhadap segala keadaan dan urusan mereka, maka sangat tidak logis jika ada yang menjadikan ilah dari makhlukmakhlukNya yang sangat membutuhkanNya. Jika tidak mungkin ada makhluk yang menjadi ilah, maka sudah pasti bahwa pencipta semua makhluk tersebut adalah ilah yang nyata dan sesembahan yang benar.

\section{PENUTUP}

Dari pembahasan di atas dapat disimpulkan bahwa :

1. Adat Mappalili merupakan serangkaian upacara adat khas Karaeng Marusu yang pada intinya adalah turunnya alat-alat kerajaan menuju sawah kerajaan yang bergelar Turannu untuk meluku (membajak) area persawahan dengan memakai benda pusaka Pajekkona Karaenga ri Marusu yang dilaksanakan secara adat, hal ini dilaksanakan setiap tahun sejak dahulu kala oleh para leluhur mereka sebagai bentuk budaya.Yang dilaksanakan setiap tahunnya yaitu pada bulan November;

2. Respon baik dari masyarakat terhadap ritual adat Mappalili sangatlah besar, mereka masih mempedomani dan masyarakat yang menggarap sawah serta kelompok tani sepakat dengan pemilik sawah untuk tidak memulai kegiatan menggarap sawah-sawah mereka sebelum acara ritual adat Mappalili di selenggarakan. Masyarakat pun sangat bersinergi untuk memajukan adat istiadat yang diadakan di Balla Lompoa yang di mana pemerintahan terdahulu berada dalam naungan Balla Lompoa;

3. Ritual Adat Mappalili dan segala rangkaian acaranya, di antaranya pa'jeko, memukul gendang dengan iringannya, doa dan pengharapan terhadap pesta ini adalah bertentangan dengan tauhid Rububiyab dan Ulubiyah Allah swt. Sesungguhnya Rububiyah Allah swt yang tetap tanpa ada perselisihan itu menuntut dan mewajibkan UlubiyabNya. Bahwasanya, Rabb yang menghidupkan, dan mematikan, memberi dan mencegah, memberi manfaat dan mudharat. Dialah yang berhak terhadap peribadatan para makhlukNya dan lebih wajib untuk dijadikan sebagai ilah dengan ditaati, dicintai, diagungkan, disucikan dan ditaati.

\section{DAFTAR PUSTAKA}

Al-Qur'àn al-Karim dan Terjemahnya Al Jazairy, Syaikh Abu Bakar Jabir. (2014). Minbajul Muslim, Terj, Ikhanuddin Abdullah dan Taufik Aulia Rahman, Pedoman Hidup Harian Seorang Muslim. Jakarta: Ummul Qura, 2014.

Bin Ayyub, Ahmad bin Sulaiman. (2004). al-Badru al-Munir jilid 9, Cet 1; Riyad: Darul Hibrah Linnasri Wattausi' 2004.

16 Departemen Agama RI, al-Qur'an dan Terjemahannya. (t.Cet;Bandung: PT Sygma Examedia Arkanleem), h. 24. 
NUKHBATUL 'ULUM : Jurnal Bidang Kajian Islam

Vol. 5, No. 1 (2019) : Hal. 15-25

Website: https://journal.stiba.ac.id

ISSN : 2685-7537 (online) 2338-5251 (Printed)

http://www.marosfm.com/2015/11/kendatielnino-upacara-adat-mappalili-dimaros-tetap-dilaksanakan-sesuaijadwal-tahunan, (diakses pada tanggal 14 Mei 2018).

http://youchenkymayeli.blogspot.com./2012 L10/upacara-mappalili-turun-sawahdi.html, (diakses pada tanggal 31 maret 2018). 